\title{
MODELING THE COOLING EFFECT OF THE CUTTING FLUID IN MACHINING USING A COUPLED FE-CFD SIMULATION
}

\author{
H. Liu ${ }^{1 *}$, T. Helmig ${ }^{2}$, T. Augspurger ${ }^{1}$, N. Nhat ${ }^{2}$, R. Kneer ${ }^{2}$, T. Bergs ${ }^{1}$ \\ ${ }^{1}$ Laboratory for Machine Tools and Production Engineering (WZL) of RWTH Aachen University, Aachen, Germany \\ ${ }^{2}$ Institute of Heat and Mass Transfer of RWTH Aachen University, Aachen, Germany \\ *Corresponding author; e-mail: h.liu@wzl.rwth-aachen.de
}

\begin{abstract}
The cooling with cutting fluids is a complex process in manufacturing, since chemical, mechanical and thermal phenomena occur simultaneously. The experimental methods developed so far do not allow for a direct observation of the coolant flow during machining, which limits the understanding of the cooling mechanism. The main aim of this paper is the investigation of convective heat transfer between cutting fluid and the cutting zone as well as the heat flow distribution on the tool surface during the cutting process by means of a coupled FE-CFD simulation. The FE model calculates the heat generation under consideration of the experimentally validated punctual, transient tool temperature during the machining processes. Based on the result of the $\mathrm{FE}$, the subsequent CFD simulation performs the calculation of the flow behavior and convective heat transfer. This method allows a detailed investigation of the temperature field in the cutting zone under consideration of the cutting fluid. The simulation returns spatially resolved heat transfer coefficients along the tool surface and provides first findings for an improvement of heat removal efficiency by changing the coolant supply parameters and the physical properties of the cutting fluid. The model parameters were validated by comparing the simulation results and the measured punctual tool temperature.
\end{abstract}

\section{Keywords:}

Orthogonal cutting; Coupled FE-CFD simulation; Tool cooling; Heat transfer

\section{INTRODUCTION}

In today's globalized world, manufacturing companies must develop production processes that best meet the needs of their customers to achieve maximum economic efficiency. A market study of 1157 companies in the German metal and electrical industry shows a trend towards an increasing number of product variants and rapidly rising demands on production accuracy [Kinkel2005]. The results indicate that the current priority to improve economic efficiency is to increase machining accuracy and flexibility while maintaining productivity.

One of the main factors that affect accuracy and machinability is the heat generated during the machining process. During the cutting process, about $90 \%$ of the mechanical energy is converted into heat and leads to high local temperatures in the cutting zone [Klocke2018]. The high temperature together with the mechanical stress accelerates the tool wear on the one hand and thus restricts productivity. On the other hand, thermomechanical loads can change the surface properties of the workpiece and significantly influence the functional performance of the manufactured parts [Augspurger2020].
To suppress the negative effects of thermal loads, cutting fluids are used in the manufacturing process. The main objectives of using cutting fluid is to increase tool life, facilitate chip breakage and chip removal and ensure the dimensional accuracy of the machined surface [Astakhov2012]. The use of cutting fluid and the systematic study of their cooling-lubricating effects can be traced back to the late 19th century. Taylor summarized the investigations conducted between 1881 and 1906 to improve the performance and productivity of cutting processes [Taylor1906]. By directing a focused water jet at the chip top side, the chip removal rate was increased by $40 \%$. Brinksmeier et al. investigated the effect of cutting fluid on the milling of titanium alloy and reported that flood cooling can increase tool life by more than two times [Brinksmeier1999]. It was also observed that the cutting fluid lowers the tool temperature and thus reduces the occurrence of weld chips on the tool surface. Furthermore, the cutting fluid changes local thermal-mechanical loads, which can have a significant impact on the surface integrity of the workpiece. Devillez et al. compared the residual stresses on the workpiece surface under wet and dry conditions and found that the coolant reduced the surface tension stresses [Devillez2011]. 
Although the positive effects of the cutting fluid are recognized and widely used in the industry, there are some disadvantages associated with the use of coolants. On the one hand, the maintenance and disposal of the cutting fluid as well as the supply system cause additional costs. Surveys in the German automotive industry have shown that the cost of manufacturing parts related to cooling lubricants is several times higher than the cost of tools [Klocke1993]. On the other hand, with the widespread use of high-speed machining, the effect of flood cooling is reduced or even negligible, especially in continuous machining. Sadat et al. investigated the effect of flood cooling on cutting force and surface integrity in continuous turning of Inconel 718 and observed that the influence of coolant is negligible under high speed cutting conditions [Sadat1987]. Kitagawa et al. investigated the influence of cutting fluid on the tool temperature in continuous and intermittent cutting [Kitagawa1997]. The experimental results showed that the cooling effect was negligible during continuous cutting, but significant during intermittent cutting. One possible explanation for this phenomenon is that during continuous high-speed machining, the coolant cannot penetrate the tool workpiece interface due to the high temperatures in the cutting zone. However, this explanation is still a hypothesis.

The effect of cutting fluid depends on various factors and its efficiency can only be maximized if the fundamental acting mechanism of cutting fluid is understood and the control variable of the supply system is optimally adapted to the cutting conditions. The local flow behavior plays an essential role for the cooling effect of cutting fluid. However, due to the optical inaccessibility during the cutting process, it is not possible to directly observe the flow behavior of the coolant in the cutting zone. Therefore, most of the cooling parameters determined by the experimental investigation were only valid for the cutting conditions used in the experiment. As a supplement to the experimental method, Computational Fluid Dynamics (CFD) has been widely used in coolant design. Beer et al. improved the flank face design of a carbide twist drill based on CFD analysis and achieved a performance increase of about 50\% [Beer2014]. Fang doubled the tool life in turning by adding cooling channels on the flank face [Fang2017]. The CFD simulation showed that the improvement in coolant effectiveness was related to hydraulic pressure values and gradient. Although the simulative investigations conducted so far have provided a better understanding of the fluid properties in the cutting area, most simulation models did not consider the chip formation process and particular chip geometry, so that the simulation results are not sufficiently accurate for quantitative investigations. Therefore, new simulation approaches are required to simulate the thermomechanical coolant effect of coolant under consideration of the chip formation process.

Oezkaya et al. linked the FE chip formation simulation of the twist drilling to the thermal coupled CFD simulation via an interface program [Oezkaya2019]. The simulation results revealed that even small chips can cause a significant decrease in flow rate, which can reduce tool life and lead to poor chip evacuation. Previously a simulation interface for combining chip formation simulation with CFD simulation was presented by the authors [Liu2020] [Helmig2019]. In the present work, the interface is further developed and used to investigate convective heat transfer between cutting fluid and the cutting zone as well as the heat flow distribution on the tool surface during the orthogonal cutting process.

In the following chapter, the experimental setup for orthogonal cutting with cutting fluid supply is presented. Thereby the tool temperature and cutting force are measured and used as validation data for the cutting simulation. Chapter 3 presents the working principle of the applied simulation models. This enables a better understanding for the later analysis of the simulation results. The subsequent analysis of the results reveals the cooling mechanism of the coolant. This serves as a guideline for the optimization of the cooling systems. In conclusion, the advantages and shortcomings of the simulation method are summarized and an outlook on the further development of the simulation will be given.

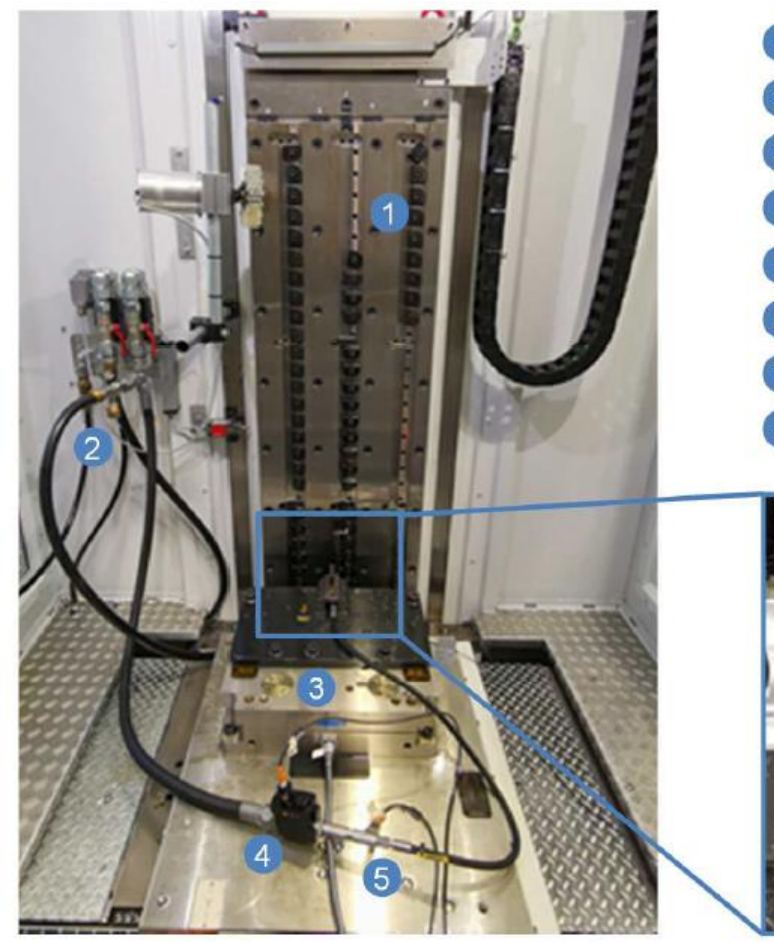

Broaching slide with workpiece clamp

2 Coolant supply

3 Multi-component dynamometer

4 Flow transmitter

5 Pressure transmitter

6 Workpiece specimen

(7) Cutting tool and tool holder

8 Quartz fiber

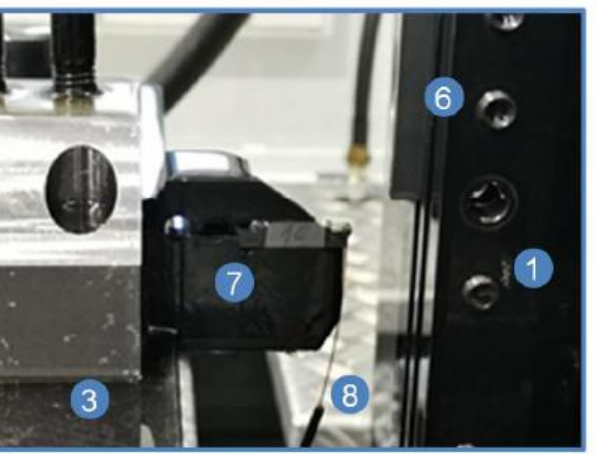

Fig. 1: Experimental setup of the orthogonal cutting experiment on a broaching machine with coolant supply 


\section{EXPERIMENTAL PROCEDURE}

Firstly, orthogonal cutting experiments were performed to create a database for the model validation. This chapter presents the experimental setup and procedure as well as the workpiece material and cutting tools used in the experiments.

\subsection{Experimental setup and procedure}

The tests were performed on a vertical broaching machine type RASX $8 \times 2200 \times 600 \mathrm{M}$ from Forst Technologie $\mathrm{GmbH}$, as shown in Fig. 1. The workpiece specimen in sheet form was clamped on the broaching slide. A customized grooving insert was clamped on a standard tool holder QS-LF123H20C2525E from Sandvik Coromant and mounted on the worktable together with the Kistler Z21289 dynamometer. During the test, the broaching slide moved at a constant speed from top to bottom against the tool, thus providing an orthogonal cutting process. The cutting oil Variocut B 9 from Castrol was used as coolant. Its properties are shown in Tab. 1.

Tab. 1: Properties of Castrol Variocut B9 [Castrol2016], [Denkena2011]

\begin{tabular}{ccc}
\hline Property & Unit & Data \\
\hline Appearance & - & Yellow \\
Kinematic viscosity at $40{ }^{\circ} \mathrm{C}$ & $\mathrm{mm}^{2} \cdot \mathrm{s}^{-1}$ & 11 \\
Density at $15^{\circ} \mathrm{C}$ & $\mathrm{kg} \cdot \mathrm{m}^{-3}$ & 870 \\
Specific heat & $\mathrm{J} \cdot \mathrm{kg}^{-1} \cdot \mathrm{k}^{-1}$ & 1950 \\
Thermal conductivity & $\mathrm{W} \cdot \mathrm{m}^{-1} \cdot \mathrm{k}^{-1}$ & 0.13 \\
\hline
\end{tabular}

The cutting oil was supplied by a centrifugal pump with a constant pressure of 5 bar. The flow rate and pressure were monitored by sensors installed on the supply hose. The coolant was injected through the inner cooling channel of the tool holder to the cutting edge. Thereby the flank face cooling was closed and only the rake face cooling was used. Alignment of the coolant nozzle was measured with a coordinate measuring machine. The angle between nozzle alignment and the tool rake face was $23.3^{\circ}$.

During the test, both the cutting force $\mathrm{F}_{\mathrm{c}}$ and the thrust force $F_{t}$ were measured with the dynamometer. The tool temperature $\mathrm{T}_{\text {tool }}$ near the cutting edge was measured with a ratio pyrometer. For this purpose, a glass fibre was installed in the cutting tool. The infrared radiation transmitted through the glass fiber to the pyrometer. Fig. 2 gives the installation position of the glass fiber. The technical data of the applied sensors are listed in Tab. 2.

Tab. 2: Overview of the applied sensors

\begin{tabular}{cccc}
\hline Sensor type & Model & $\begin{array}{c}\text { measuring } \\
\text { range }\end{array}$ & $\begin{array}{c}\text { sampling } \\
\text { rate }\end{array}$ \\
\hline Dynamometer & $\begin{array}{c}\text { Kistler } \\
\text { Z21289 }\end{array}$ & -80 to $80 \mathrm{kN}$ & $50 \mathrm{kHz}$ \\
$\begin{array}{c}\text { Flow } \\
\text { transmitter }\end{array}$ & $\begin{array}{c}\text { IFM } \\
\text { SBU625 }\end{array}$ & 0.3 to $75 \mathrm{l} / \mathrm{min}$ & $100 \mathrm{~Hz}$ \\
$\begin{array}{c}\text { Pressure } \\
\text { transmitter }\end{array}$ & $\begin{array}{c}\text { IFM } \\
\text { PT5502 }\end{array}$ & 0 to $100 \mathrm{bar}$ & $500 \mathrm{~Hz}$ \\
$\begin{array}{c}\text { 2-colour } \\
\text { Pyrometer }\end{array}$ & $\begin{array}{c}\text { en2Aix } \\
\text { FIRE-1 }\end{array}$ & 200 to $1200{ }^{\circ} \mathrm{C}$ & $500 \mathrm{kHz}$ \\
\hline
\end{tabular}

The experiments were performed under dry and wet conditions with a cutting speed of $v_{c}=50 \mathrm{~m} / \mathrm{min}$ and an undeformed chip thickness of $h=75,125$ and $175 \mu \mathrm{m}$. Each test was repeated two times and a new cutter was used to ensure the reliability of the measurement.

\subsection{Cutting tools and Workpiece materials}

The cutting tool was customized by Sandvik Coromant with a rake angle of $y=12^{\circ}$ and a clearance angle of $\alpha=3^{\circ}$ without chip breaker. The tool material was cemented carbide type H13A. The cutting-edge rounding was measured with the optical measuring system MicroCAD from LMI TECHNOLOGIES. All tools showed a cuttingedge rounding in the range of $5 \pm 0.2 \mu \mathrm{m}$. To attach the glass fibre near the cutting edge, all tools were drilled with electro-discharge machining. The distance between the axis of the hole and the tool flank face was $0.6 \mathrm{~mm}$. The end of the hole had a distance of $0.3 \mathrm{~mm}$ from the rake face of the tool, see Fig. 2.

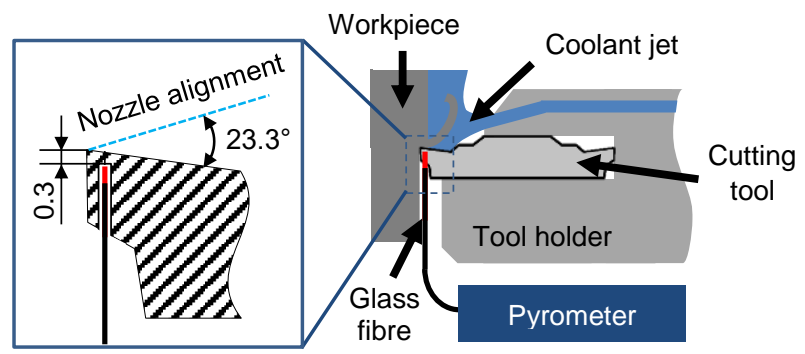

Fig. 2: Mounting position of the glass fibre

The test material was precipitation hardened nickel-based alloy Inconel 718. Due to its good creep and corrosion resistance and ability to maintain high strength at elevated temperatures, Inconel 718 has been widely used in aircraft gas turbines, steam turbine power plants, nuclear power systems and other high temperature applications [Choudhury1998]. However, the properties of Ni-based alloys result in poor machinability, and the low thermal conductivity often leads to high temperature at the tip of the tool [Ezugwu1999]. The Inconel 718 material samples used in this work were prepared into sheets of $120 \times 40 \times 2.5 \mathrm{~mm}$. The hardness of the sample was measured as $425 \pm 5 \mathrm{HV}$ 30 . The microstructure showed a homogeneous grain size distribution, see Fig 3.

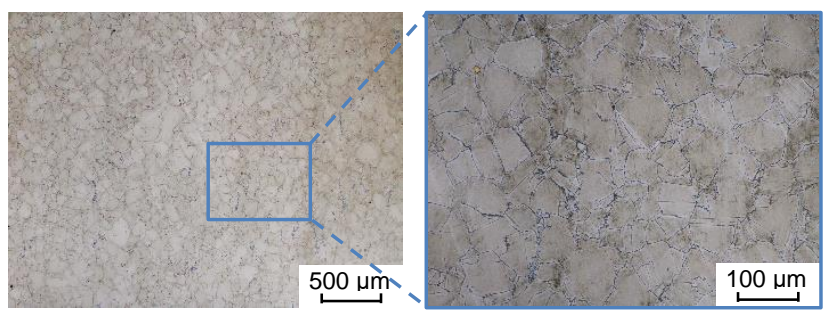

Fig. 3: Microsections of Inconel 718

Other material properties of the sample were obtained from the specifications of the manufacturer, as shown in Tab 3.

Tab. 3: Material properties of Inconel 718 (at $20^{\circ} \mathrm{C}$ )

\begin{tabular}{ccc}
\hline Property & Unit & Data \\
\hline Density & $\mathrm{kg} \cdot \mathrm{m}^{-3}$ & 8220 \\
Young's modulus & $\mathrm{GPa}$ & 217 \\
Thermal conductivity & $\mathrm{W} \cdot \mathrm{m}^{-1} \cdot \mathrm{k}^{-1}$ & 10.31 \\
Specific heat & $\mathrm{J} \cdot \mathrm{kg}^{-1} \cdot \mathrm{k}^{-1}$ & 440
\end{tabular}




\section{NUMERICAL METHOD}

The numerical approach used in this paper is based on the combination of chip formation simulation and computer fluid dynamic (CFD) simulation. The chip formation simulation was based on the Finite Element Method (FEM) to calculate the chip development, the heat generation, and the temperature change in the cutting zone. In a defined time step, the FEM results were transferred into the CFD simulation. Based on the result of the chip formation simulation, the CFD simulation was performed to calculate the fluid flow behavior and convective cooling of the cutting fluid. The data transfer between the two simulations was enabled by an interface based in the programming language Python. The working principle of this software was explained in detail in [Liu2020]. The data transfer from the FE to the CFD was unidirectional and performed at the defined time step of the chip formation simulation. Mechanical interactions between the fluid and the chip were not considered. Since low pressure cooling (5 bar) was investigated in this work, it was assumed that neglecting the mechanical effects of the coolant has no influence on the results. In the following subchapters, the simulation models and parameters used in the chip formation and CFD simulations are presented.

\subsection{FEM chip formation simulation}

The chip formation simulation was performed in the commercial software ABAQUS using the Coupled-EulerianLagrangian (CEL) method. The CEL method allows the material to flow through the mesh. The general approach is to perform a Lagrangian timestep and then use a remap step to map the solution from a distorted Lagrangian mesh to a spatially fixed Eulerian mesh [Benson1992]. This method avoids mesh distortion and numerical instability due to large deformations and is therefore suitable for cutting simulations. The model setting of the 2D-orthogonal cutting simulation with the CEL method is shown in Fig. 4. The initial workpiece was defined on the Eulerian domain and has a velocity boundary condition according to the cutting speed. The cutting tool was discretized with Lagrangian meshes and considered as a rigid body, therefore wear and deformation of the tool were neglected.

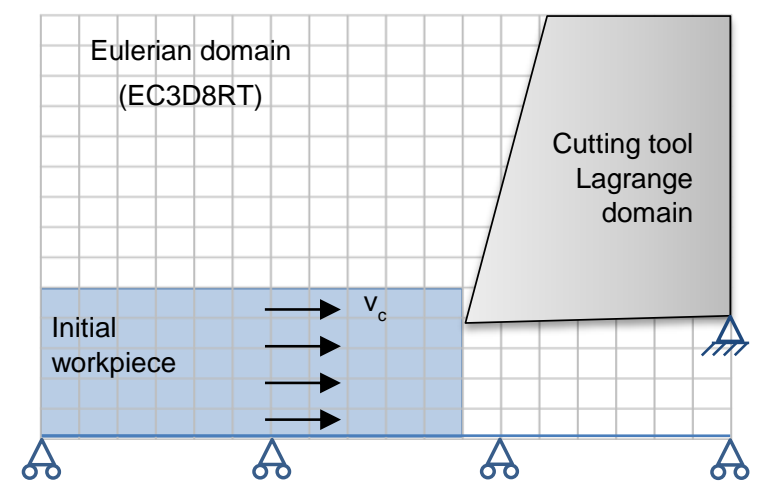

Fig. 4: Model setup of 2D-orthogonal cutting with the CELmethod

The elastoplastic behavior of workpiece materials was defined by the standard Johnson-Cook model, see equation (1) [Johnson1983].

$$
\sigma=\left(A+B \cdot \epsilon^{n}\right)\left(1+C \ln \left(\frac{\dot{\epsilon}}{\dot{\epsilon}_{0}}\right)\right)\left(1-\left(\frac{T-T_{0}}{T_{m}-T_{0}}\right)^{m}\right)
$$

The chip shape of Inconel 718 is serrated, which is caused by the adiabatic shear and damage-related crack initiation and propagation [Ozel2009]. To simulate this chip formation process, the Johnson Cook damage criterion was used. The expression is as in (2).

$$
\begin{aligned}
\epsilon^{f=} & \left(D_{1}+D_{2} \exp \left(D_{3} \cdot \frac{\sigma_{m}}{\bar{\sigma}}\right)\right) \cdot\left(1+D_{4} \ln \left(\frac{\dot{\epsilon}}{\dot{\epsilon}_{0}}\right)\right) . \\
& \left(1+D_{5}\left(\frac{T-T_{0}}{T_{m}-T_{0}}\right)^{m}\right)
\end{aligned}
$$

The model parameter for Inconel 718 used in this work was derived from the empirical study by Erice [Erice2014]. Since the material studied in this work differs slightly from that analyzed by Erice, the parameter $D_{2}$ of the damage model were inversely calibrated with the cutting force.

Another important model for chip formation simulation is the friction model, since friction has a major influence on deformation in the primary shear zone, chip thickness, chip flow direction, cutting force and temperature [Abouridouane2015]. The friction behavior between tool and workpiece cannot be adequately described by the Coulomb friction model. Therefore, a temperature dependent friction model was used in this paper [Puls2014]. The friction coefficient can be expressed as follows:

$$
\begin{array}{ll}
\mu=\mu_{0} & \text { for } \mathrm{T}<\mathrm{T}_{0} \\
\mu=\mu_{0} \cdot\left(1-\left(\frac{T-T_{f}}{T_{m}-T_{f}}\right)^{m_{f}}\right) & \text { for } \mathrm{T} \geq \mathrm{T}_{0}
\end{array}
$$

The model parameter for contact pairing of Inconel 718 and carbide as determined by Seimann et al. was used in the simulation [Seimann2018].

The above-mentioned simulation models have been implemented and explicitly solved in ABAQUS (Version

\begin{tabular}{|c|c|c|c|c|c|c|}
\hline \multicolumn{7}{|c|}{ Johnson Cook material constitutive model } \\
\hline A & B & $\mathrm{C}$ & $\mathrm{m}$ & $\mathrm{n}$ & $\mathrm{T}_{\mathrm{m}}$ & $\dot{\epsilon}_{0}$ \\
\hline [MPa] & {$[\mathrm{MPa}]$} & - & - & - & {$\left[{ }^{\circ} \mathrm{C}\right]$} & {$\left[{ }^{\circ} \mathrm{C}\right]$} \\
\hline 1200 & 1284 & 0.006 & 1.2 & 0.54 & 1800 & $10^{-3}$ \\
\hline \multicolumn{7}{|c|}{ Johnson Cook damage model } \\
\hline \multicolumn{2}{|l|}{$\mathrm{D}_{1}$} & $\mathrm{D}_{2}$ & \multicolumn{2}{|l|}{$\mathrm{D}_{3}$} & $\mathrm{D}_{4}$ & $D_{5}$ \\
\hline \multicolumn{2}{|l|}{0.04} & 1.2 & \multicolumn{2}{|l|}{-1.45} & 0.04 & 0.89 \\
\hline \multicolumn{7}{|c|}{ Friction model } \\
\hline \multicolumn{3}{|c|}{$\mu_{0}$} & \multicolumn{2}{|l|}{$m_{f}$} & \multicolumn{2}{|r|}{$T_{f}$} \\
\hline \multicolumn{3}{|c|}{-} & \multicolumn{2}{|l|}{-} & \multicolumn{2}{|r|}{$\left[{ }^{\circ} \mathrm{C}\right]$} \\
\hline \multicolumn{3}{|c|}{0.46} & \multicolumn{2}{|l|}{2.4} & \multicolumn{2}{|r|}{200} \\
\hline
\end{tabular}
6.14). The minimum mesh size of the model was defined in the cutting area as $6 \mu \mathrm{m}$. Tab. 4 summarizes the model parameters used in this work.

Tab. 1: Overview of the model parameters

The FEM chip formation simulation generated geometric and thermal boundary conditions for the fluid simulation. The data exchange between the FEM and the fluid simulation is achieved through an interface program. The workflow of the program is shown in Fig. 5.

The interface program used Python to read the ABAQUS simulation results and generated a VTK file containing the physical results and geometry of the parts. Based on the VTK file, the solid geometry required for the CFD simulation was generated using the open-source software Paraview. Since the boundary layer mesh required for CFD simulation was different from FE simulation, there was no mesh information transferred. The CFD simulation created a new mesh based on the geometric model using the mesh generator snappyHexMesh. 


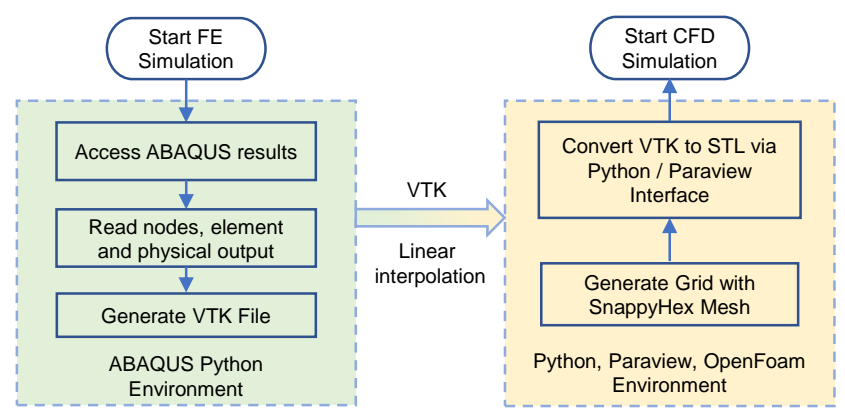

Fig. 5: Major working procedures of the interface program

The temperature field of the FE results was imported into the CFD simulation as an initial condition. Since the meshes of the two simulations were different, the physical parameters between the mesh nodes are derived using linear interpolation. In CFD, the heat generation and heat distribution in the cutting zone are defined as the heat load. Once the physical data was imported, the parameters of the CFD model could be set to calculate the convection cooling of the cutting fluid. The whole simulation process was managed by a Python script so that the data transfer could be done automatically. The following chapter describes the specific settings of the CFD.

\subsection{CFD Simulation}

The CFD framework was provided by the Open Source CFD Software package OpenFoam (Version 6.0) which applies the finite volume approach to discretize and solve the conservation equation of mass, momentum and energy for the solid- as well as for the fluid phase.

$$
\begin{aligned}
& \frac{\partial \rho}{\partial t}+\frac{\partial \rho u_{i}}{\partial x_{i}}=0 \\
& \frac{\partial \rho u_{i}}{\partial t}+u_{j} \frac{\partial \rho u_{i}}{\partial x_{j}}=\frac{\partial p}{\partial x_{i}}+\mu \frac{\partial^{2} \rho u_{i}}{\partial x_{j}^{2}} \\
& \frac{\partial \rho h}{\partial t}+\frac{\partial \rho u_{i} h}{\partial x_{i}}=a \frac{\partial^{2} h}{\partial x_{j}^{2}}+\dot{q}^{\prime \prime \prime}
\end{aligned}
$$

While the solid phase contains two different regions for tool and chip / workpiece considering different materia properties, the fluid phase, in contrast, only modelled the liquid lubricant. This simplification was made, as prior investigations have shown, that the interaction between surrounding gaseous air and liquid lubricant is neglectable, and the majority of the fluid domain is filled by the liquid.

Regarding the modeling of thermal phenomena, the following aspects were considered: First, lubricant and solid are connected with a thermal coupling boundary condition in the energy equation to account for convective heat transfer along tool, chip and workpiece. Second, a heat source term was utilized in the energy equation of the solid region to model the dissipation of mechanical energy during the cutting process, see equation 6 . Therefore, the averaged local heat flux calculated from FEM simulation was applied homogeneously along the interface between tool and fluid, as shown in Fig. 6. It needs to be stressed, that this heat flux was determined under dry cutting conditions and did not consider reduced source terms due to lower friction. However, experiments for this material combination have shown only a minor decrease in cutting force. Therefore also only a corresponding minor decrease in the heat source term is expected.
In addition, to model the continuous supply with new workpiece material at ambient temperature, a velocity field is applied in the solid region.

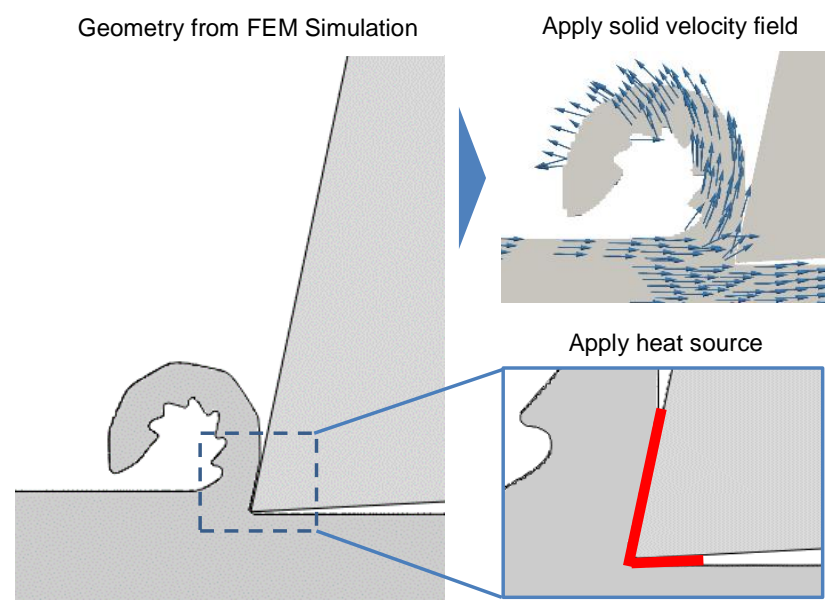

Fig. 6: Geometry, velocity field and heat source Application for CFD simulation setup.

Besides the solid geometry and velocity, the angle and direction of the fluid flow need to be specified, which is shown in Fig. 7. All simulations were performed with a constant geometry considering tool, flow angle as well as the chip contour. Fig. 7 also shows the nomenclature of the occurring boundary conditions $\Omega$ with the corresponding correlations and nomenclature outlined in Tab. 5.

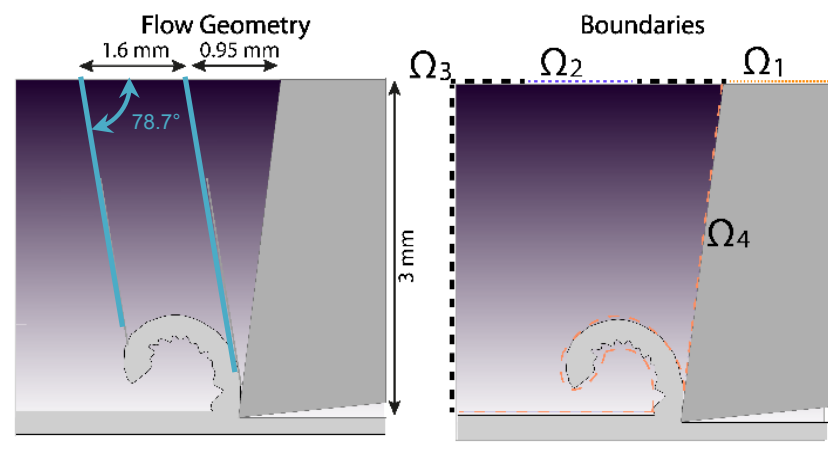

Fig. 7: Geometry setup and location of boundary conditions

Tab. 5: Applied Boundary Conditions

\begin{tabular}{ccccc}
\hline Field & $\mathbf{\Omega 1}$ & $\mathbf{\Omega 2}$ & $\mathbf{\Omega 3}$ & $\mathbf{\Omega 4}$ \\
\hline Velocity & - & Inlet & Outlet & No slip \\
& & & & \\
Temperature & Fixed & Fixed & Zero & coupled \\
& Value & Value & gradient & \\
Pressure & - & $\begin{array}{c}\text { Ambient } \\
\text { pressure }\end{array}$ & $\begin{array}{c}\text { Zero } \\
\text { gradient }\end{array}$ & - \\
\hline
\end{tabular}

As the major aim of this work is the investigation of cooling effects under low fluid flow pressure, changes in chip geometry due to fluid stagnation are neglectable. However, the impacts of high fluid pressure and corresponding changes in geometry will be addressed in future work. 


\section{RESULTS AND DISCUSSION}

Since approx. $90 \%$ of the mechanical energy is converted into thermal energy during the cutting process, the agreement of the simulated cutting force with the experimental results is a prerequisite for the modeling of primary heat source and cooling effect of the cutting fluid. Therefore the cutting force in the stationary state of the measuring signal and the tool temperature were analyzed. Fig. 8 shows the development of cutting force and tool temperature over time, measured under dry machining conditions.

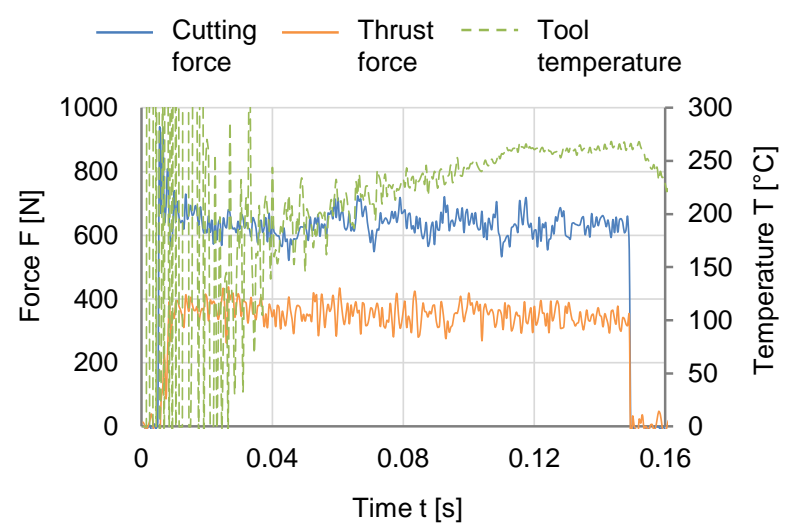

Fig. 8: Process force and tool temperature measurement

After 0.04 seconds, the process force tends to stabilize. The mean value of the process force in steady state was used as the reference value for the validation of material model. The ratio pyrometer used in this work has a measurement range of $200-1200^{\circ} \mathrm{C}$. Outside of the range, the measurement curve is only a noise signal. At the end of the cut the tool temperature has still not reached a steady state value, so that the transient tool temperature at the end of the cut was used as reference value for the calibration of the thermal model. Fig. 9 shows a comparison of the experimentally measured cutting forces under wet and dry conditions with the simulation. The results show that under the impact of the cutting fluid the change in cutting force is very small. With the validated material model, the cutting forces could be simulated accurately, but the thrust forces were highly underestimated. Since the thrust force is perpendicular to the cutting velocity, the process work and primary heat generation depend only on the cutting force and the deviation of the thrust force has no influence on the results of the thermal analysis.

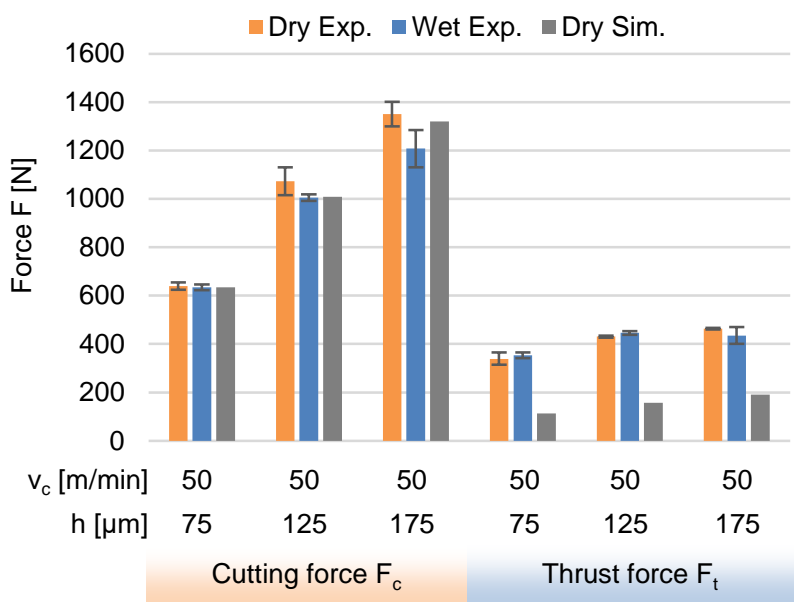

Fig. 9: Cutting force and thrust force obtained from experiment and simulation

Fig. 10 shows the experimentally measured tool temperature compared to the simulation results. The tool temperature with consideration of cutting fluid was simulated in the CFD simulation.

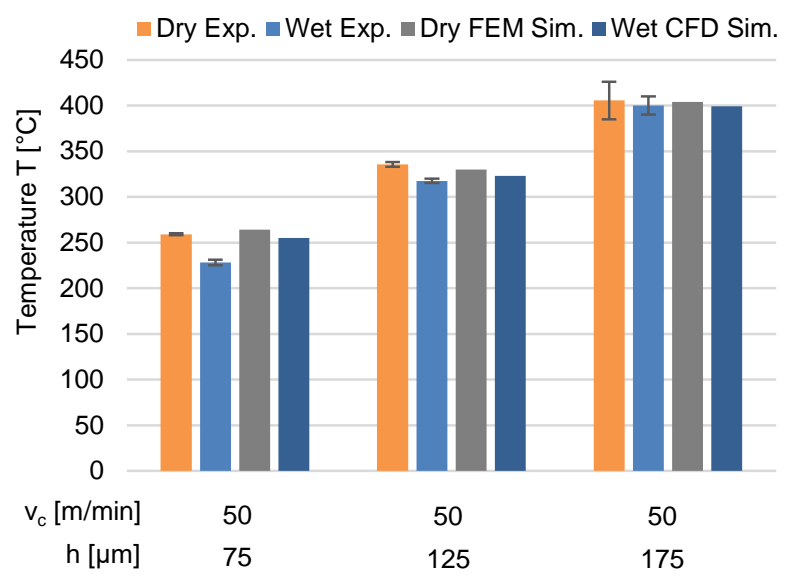

Fig. 10: Tool temperature obtained from experiment and CFD simulation
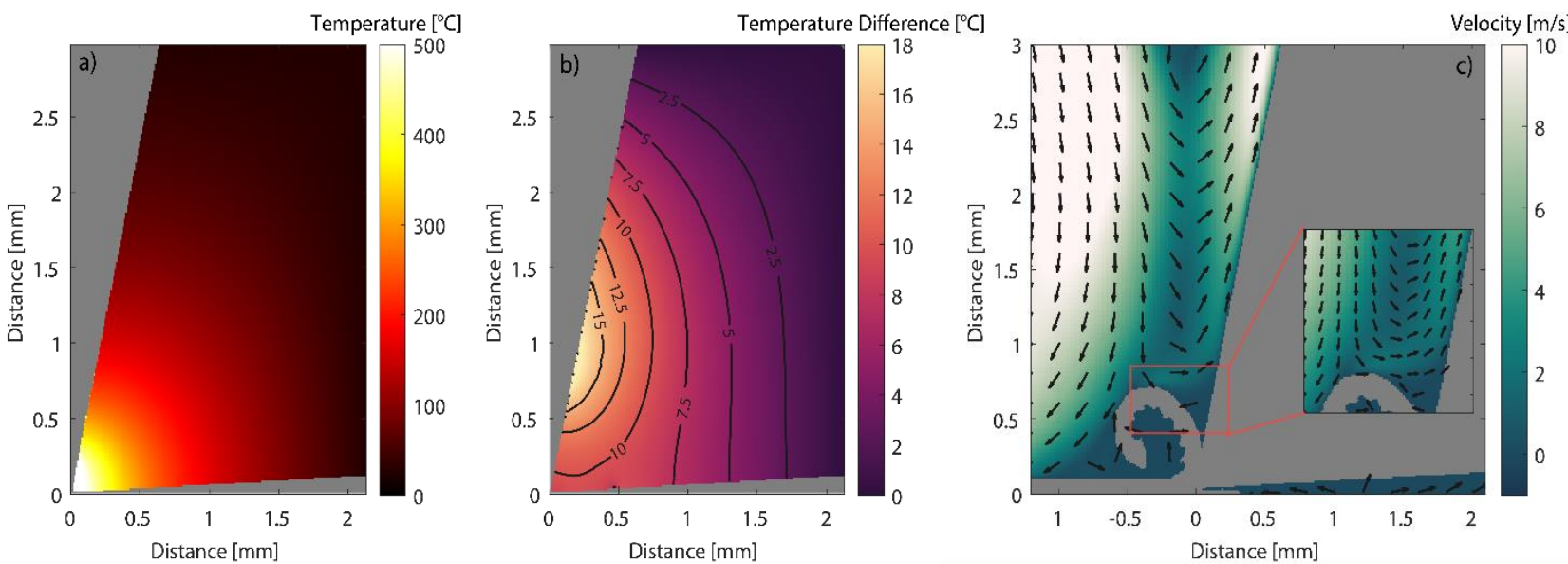

Fig. 11: Contour Plots from CFD Simulation ( $\left.v_{c}=50 \mathrm{~m} / \mathrm{min}, h=75 \mu \mathrm{m}, t=0.15 \mathrm{~s}\right)$ : Tool Temperature (a), Temperature difference between dry and wet cutting conditions (b) and lubricant velocity profile close to the solid-fluid interface (c) 
To give a general overview of the results obtained from the CFD simulation, Fig. 11 shows contour plots of the too temperature as well as the velocity close to the toollubricant interface $\left(v_{c}=50 \mathrm{~m} / \mathrm{min}, \mathrm{h}=75 \mu \mathrm{m}\right)$. First, Fig. 11a) shows the tool temperature revealing that the highest temperatures occur close to the cutting edge, where also the majority of heat source is located.

Besides the absolute temperature, Fig. 11b) shows the difference in tool temperature obtained from CFD simulation performed with and without application of cutting fluid. Isolines are also visualized to emphasize the trend of local temperature differences. Regarding the pure convective cooling effect, temperature differences in range between 0 to $20^{\circ} \mathrm{C}$ are obtained. The highest temperature difference occurs at $0.6-0.75 \mathrm{~mm}$ distance from the tool tip at the rake face. However, with increasing radial distance from this location the cooling effect decreases, still showing some minor effects at the flank face which has no immediate contact with the cooling fluid. Further, Fig. 11c) shows the velocity profile of the cooling lubricant, providing additional data for the interpretation of the presented temperature fields. In general, the chip causes a redirection of the flow and prevents the infiltration of cutting fluid into the cutting zone. Hence, a stagnation zone forms at the tool-chip interface caused by this narrow geometry. Above the stagnation zone, the fluid accelerates up to several meters per second along the rake face and finally reaches about $10 \mathrm{~m} / \mathrm{s}$.

This effect is also visible in Fig. 12 showing the heat flux along the rake face. Below a tool tip distance of $0.5 \mathrm{~mm}$ no heat flux at fluid and tool-chip contact zone occurs. However, afterwards a fast increase with a following peak is visible, which finally falls off again. Further, Fig. 12 illustrates the impact of increasing cutting depth and corresponding chip size on the local heat flux. In general, a shift in heat flux to larger distances to the tool edge can be observed. Due to larger chips, less cooling lubricant enters the cutting zone leading in particular for a $175 \mu \mathrm{m}$ cut to a decrease in convective heat flux.

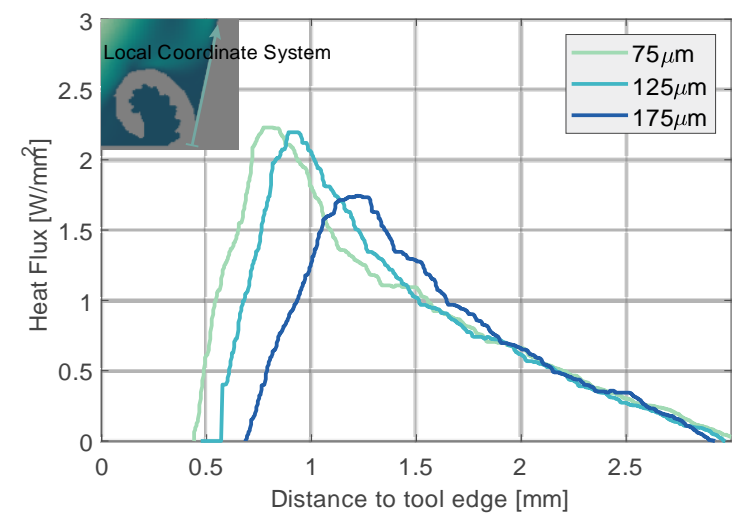

Fig. 12: Heat Flux from the tool to the lubricant along the rake face for three different cutting depths

Based on the heat flux, the heat transfer coefficient is derived by using the following equation:

$$
h=\frac{\dot{q}^{\prime \prime} \text { convective }}{T_{\text {boundary }}-T_{\text {inlet }}}
$$

Similar to the heat flux, the heat transfer coefficient reaches its peak at $0.6-0.75 \mathrm{~mm}$ distance from the cutting edge. In contrast to the heat flux, the heat transfer coefficient shows afterwards a slower decline before falling off near the outlet. This behavior emphasizes, that besides the heat transfer coefficient itself also the temperature difference between fluid and solid impacts the magnitude of the local heat flux.

Fig. 13 also shows the influence of varying cutting depth, revealing similar behavior as outlined in the previous Figure: With increasing cutting depth and corresponding chip size, the heat transfer coefficients shift to larger edge distances and show decreasing mean values from 12 to about $8.5 \mathrm{~kW} / \mathrm{m}^{2} \mathrm{~K}$.

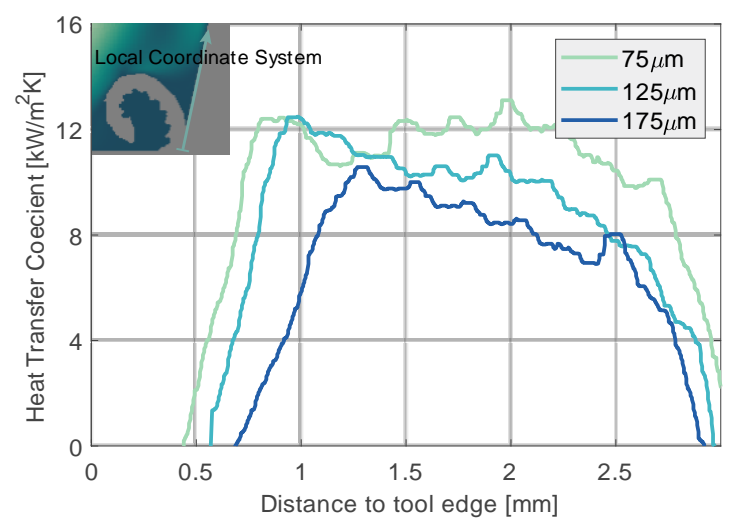

Fig. 13: Derived Heat Transfer Coefficient along the tool rake face for three different cutting depths

Since a two-dimensional simulation is used in this paper, the fluid flow laterally perpendicular to the cutting direction is not considered. Therefore, the flow velocity in the cutting zone is underestimated which is also evident from the comparison between simulation and measurement in Fig. 10. Nevertheless, the deviation of the simulation from the measured temperature under cooling conditions is about $20^{\circ} \mathrm{C}$. Since the size of the stagnation zone is related not only to the initial flow velocity but also to the chip geometry and surface motion velocity as well as the chip formation process itself and the cutting parameters, further investigation of these parameters is required.

Considering the enhancement of heat transfer in future works, two ideas are suggested: First, the nozzle position and angle can be adjusted for an improved penetration of the fluid flow at the tool chip interface. Second, the diameter of the nozzle can be adjusted to better match between flow and interface geometry.

\section{CONCLUSIONS}

In this paper, the effect of cutting fluid on tool temperature during the cutting process was investigated through orthogonal cutting experiments and corresponding numerical simulations. The experimental results showed that the effect of cutting fluid on cutting force was negligible under the investigated cutting conditions. The cooling effect on tool temperature is related to the solid-liquid temperature difference and local flow rate. Due to the chip surface velocity and the narrow gaps formed between the chip and the tool rake face, a stagnation zone regarding fluid velocity forms in the cutting zone. This limits the exchange of coolant in the cutting zone and reduces the efficiency of convective cooling.

In future studies, the presented simulation methods will be extended to three-dimensional modelling. In addition, the results show that the chip formation process has a significant influence on the cooling effect of the cutting fluid. Future research will focus on the effects of different chip geometries on transient tool temperatures and the corresponding changes in local heat transfer coefficients. 


\section{ACKNOWLEDGMENTS}

The authors would like to thank the German Research Foundation (DFG) for the funding the SFB/Transregio 96 collaborative research (Project ID 174223256-TRR 96) "Thermo-Energetische Gestaltung von Werkzeugmaschinen" subproject A02 and B02 and the depicted research within the project "Development of a 3D multiphysics model for the analysis of the thermomechanical cooling lubricant effect in machining" (KL 500/203-1).

\section{REFERENCES}

[Abouridouane2015] Abouridouane, M., Klocke, F., Lung, D., Veselovac, D., The mechanics of cutting: In-situ measurement and modelling. In: Procedia CIRP. 2015, Vol. 31, pp. 246-251

[Astakhov2012] Astakhov, V., Tribology of cutting tools. In: Tribology in Manufacturing Technology. 2012 pp. 1-66, ISBN: 978-3-642-31682-1

[Augspurger2020] Augspurger, T., Meurer, M., Liu, H., Mattfeld, P., Bergs, T., Experimental study of the connection between process parameters, thermomechanical loads and surface integrity in machining Inconel 718. In: Procedia CIRP. 2020. Vol. 87, pp. 59-64,

[Beer2014] Beer, N., Ozkaya, E., Biermann, D., Drilling of Inconel 718 with geometry-modified twist drills. In: Procedia CIRP 2014 Vol. 24 pp. 49-55

[Benson1992] Benson, D. J., Computational methods in Lagrangian and Eulerian hydrocodes. In: Computer Methods in Applied Mechanics and Engineering. $1992 \mathrm{Vol}$ 99, pp. 235-394

[Brinksmeier1999] Brinksmeier E, Walter A, Janssen R, Diersen $\mathrm{P}$, Aspects of cooling lubrication reduction in machining advanced materials. In: Proceedings of the Institution of Mechanical Engineers, vol. 213 Part B, pp. 769-778

[Castrol2016] Castrol product datasheet of Variocut B 9. BP p.I.c, 2016

[Choudhury1998] Choudhury, I. A., El-Baradie, M. A., Machinability of nickel-base super alloys: a general review. In: Journal of Materials Processing Technology, 1998 Vol. 77, pp. 278-284

[Denkena2011] Denkena, B., Tönshoff H. K., Spanen, Springer-Verlag, ISBN 978-3-642-19771-0

[Diniz2007] Diniz, A. E.; Micaroni, R., Influence of the direction and flow rate of the cutting fluid on tool life in turning process of AISI 1045 steel. In: International Journal of Machine Tools and Manufacture. 2007 Vol. 47, pp. 247254

[Erice2014] Erice, B., Galvez, F., A coupled elastoplasticdamage constitutive model with Lode angle dependent failure criterion. In, International Journal of Solids and Structures. 2014, Vol. 51, pp. 93-110

[Ezugwu1999] Ezugwu, E. O., Wang, Z. M., Machado, A. R., The machinability of nickel-based alloys: a review. In: Journal of Materials Processing Technology, 1999 Vol. 86, pp. 1-16

[Fang2017] Fang, Z., Obikawa, T., Turning of Inconel 718 using inserts with cooling channels under high pressure jet coolant assistance. In: Journal of Materials Processing Technology. 2017 Vol. 247 pp. 19-28

[Helmig2019] Helmig T, Peng B, Ehrenpreis C, Augspurger T, Frekers Y, Bergs T, Kneer R. A Coupling Approach Combining CFD and FEM Methods to Predict Cutting Fluid
Effects on the Tool Temperature in Cutting Processes. Journal of Manufacturing Science and Engineering, 14110- 2019.

[Johnson1983] Johnson, G. R., Cook, W. H., A constitutive model and data for metals subjected to large strains, high strain rates and high temperatures. In: Proceeding 7th International Symposium on Ballistics. 1983, pp. 541-547

[Johnson1985] Johnson, G. R., Cook, W. H., Fracture characteristics of three metals subjected to various strains, strain rates, temperatures and pressures. In Engineering Fracture Mechanics. 1985, Vol. 1, pp. 31-48

[Kinkel2005] Kinkel, S., Anforderungen an die Fertigungstechnik von morgen. In: Mitteilung aus der Produktionsinnovationserhebung. Vol. 37, Fraunhofer Institut System- und Innovationsforschung, Sept. 2005

[Kitagawa1997] Kitagawa T, Kubo A, Maekawa K. Temperature and wear of cutting tools in high-speed machining of Inconel 718 and Ti-6Al-6V-2Sn. In Wear. 1997. vol 202. p. $143-148$

[Klocke2018] Klocke, F., Fertigungsverfahren 1 Zerspanung mit geometrisch bestimmter Schneide. Springer Vieweg, 2018. ISBN 978-3-662-54206-4

[Klocke1993] Klocke F, Schult A, Gerschwiler K. Saubere Fertigungstechnologie - Ein Wettbewerbsvorteil von morgen? In: Wettbewerbsfaktor Produktionstechnik Aachener Perspektiven. AWK Aachener Werkzeugmaschinen-Kolloquium. 1993. ISBN: 978-3-8322398-8-6

[Liu2020] Liu, H., Helmig, T., Augspurger, T., Kneer R., Bergs, T., A novel FEM-CFD interface for multi-physical simulations to model the effects of cutting fluid on the tool temperature during orthogonal cutting. In: Thermal Issues. 26-27, Feb. 2020, Aachen, pp. 47-55. ISBN: 978-09957751-6-9

[Oezkaya2019] Oezkaya E, lovkov I, Biermann D. Fluid structure interaction (FSI) modelling of deep hole twist drilling with internal cutting fluid supply. In: CIRP Annals Manufacturing Technology 2019 vol. 68 p. 81-84

[Ozel2009] Ozel, T., Yildiz, S., Ciurana, J., Influence of material models on serrated chip formation in simulation of machining Ti-6Al-4V titanium alloy. 12th CIRP International Workshop on Modeling of Machining Operations, May 7-8, 2009, San Sebastian, Spain, Vol. 1, pp. 123-130.

[Pigott1952] Pigott, R. J. S., Hi-Jet System for increasing tool life. In: SAE Q Trans. 6, pp. 547-558

[Puls2014] Puls, H., Klocke, F., Lung, D., Experimental investigation on friction under metal cutting conditions. In: Wear. 2014, Vol. 310, pp. 63-71

[Sadat1987] Sadat A B. Surface region damage of machined inconel-718 nickel-base superalloy using natural and controlled contact length tools. In: Wear. 1987. vol 119. p. $225-235$

[Seimann2018] Seimann, M., Peng, B. X., FischersworringBunk, A., Rauch, S., Klocke, F., Model-based analysis in finish broaching of Inconel 718. In: The International Journal of Advanced Manufacturing Technology, 2018, Vol 97, pp. 3751-3760

[Sorby2006] Sorby, K.; Tonnesse, K., High-pressure cooling of face-grooving operations in Ti6Al4V. In: Proceedings of the Institution of Mechanical Engineers. Part B: Journal of Engineering Manufacture. 2006, Vol. 200 pp. 1621-1627

[Taylor1906] Taylor, F. W., On the art of cutting metals. In: The American Society of Mechanical Engineers. Trans. 28, No. 29., pp. 31-350 